\title{
Optic Neuritis in a Child With COVID-19: A Rare Association
}

\author{
Yusuf Parvez $^{1}$, Fatma AlZarooni ${ }^{2}$, Farheen Khan ${ }^{3}$ \\ 1. Pediatric Medicine, Dubai Hospital, Dubai, ARE 2. Pediatrics and Child Health, Latifa Women's and Children's \\ Hospital, Dubai, ARE 3. Pediatrics, Dubai Hospital, Dubai, ARE
}

Corresponding author: Yusuf Parvez, dryparvez@gmail.com

\begin{abstract}
The recent coronavirus disease-2019 (COVID-19) pandemic has caused significant mortality and morbidity, affecting patients of all ages. COVID-19 affects various tissues and systems in the body, including the central and peripheral nervous systems. However, COVID-19 has rarely affected the eyes and caused optic neuritis. We report a unique case of COVID-19-related unilateral optic neuritis in a 10-year-old girl.
\end{abstract}

Categories: Neurology, Ophthalmology, Pediatrics

Keywords: covid-19, optic neuritis, severe acute respiratory distress syndrome

\section{Introduction}

Coronaviruses are a group of ribonucleic acid viruses that affect birds and humans [1]. They were first discovered in the 1930s when acute respiratory tract infections were reported in domestic chickens [2]. The human coronavirus was discovered in 1960 in the United Kingdom when a boy was infected and had common cold-like symptoms [3]. Since its discovery, it has caused mild to severe infections in humans that mainly involve the respiratory tract, resulting in diseases such as severe acute respiratory syndrome, Middle East respiratory syndrome, and the recent novel coronavirus disease-2019 (COVID-19) pandemic caused by the severe acute respiratory syndrome-coronavirus-2 [4]. COVID-19 has caused significant mortality and morbidity and affects multiple organs. However, ocular manifestations have rarely been reported. We present a case of optic neuritis as a rare manifestation of COVID-19.

Review began 03/19/2021 Review ended 03/24/2021 Published 03/24/2021

(c) Copyright 2021

Parvez et al. This is an open access article distributed under the terms of the Creative Commons Attribution License CC-BY 4.0., which permits unrestricted use, distribution, and reproduction in any medium, provided the original author and source are credited.

\section{Case Presentation}

A 10-year-old previously healthy girl was admitted to our hospital with loss of vision in her left eye lasting for two days. She had no history of fever, pain in the eyes, vomiting, headache, seizures, or trauma. Her neurological examination results were normal, except her visual acuity was severely impaired in her left eye and normal in her right eye. She had no focal neurological deficit, and findings from her systemic examination were unremarkable. She was evaluated by a pediatric ophthalmologist, who indicated the patient had optic neuritis of the left eye (Figures $1 \mathrm{~A}-1 \mathrm{E}$ ). A pediatric neurologist recommended a magnetic resonance imaging (MRI) scan of her brain, spine, and orbit. The orbit's MRI revealed mild enlargement and slight T2 hyperintensity of the intracanalicular and intraorbital segment of the left optic nerve, confirming the diagnosis of left optic neuritis. The MRI of the brain and spine were unremarkable. The patient was admitted after collecting a COVID-19 polymerase chain reaction (PCR) swab test from her nasopharynx. She was screened for autoimmune optic neuritis, but the results from all investigations were unremarkable, including screens for anti-neuromyelitis optica, anti-myelin oligodendrocyte glycoprotein antibodies, aquaporin-4 antibodies, and myelin-associated glycoprotein antibodies. Her basic metabolic and immunologic work-ups and her cerebrospinal fluid studies revealed nothing remarkable. Her inflammatory markers, including C-reactive protein, procalcitonin, D-dimer, ferritin, and lactate dehydrogenase, were within reference limits.

Her COVID-19 PCR screen was positive, and she started intravenous pulsed methylprednisolone followed with oral prednisolone. Her vision improved after three days of hospital stay, and she was discharged on a tapering dose of prednisolone with home isolation for 14 days per the national guidelines. She was advised to follow-up in ophthalmology and pediatric clinics. 


\section{Cureus}
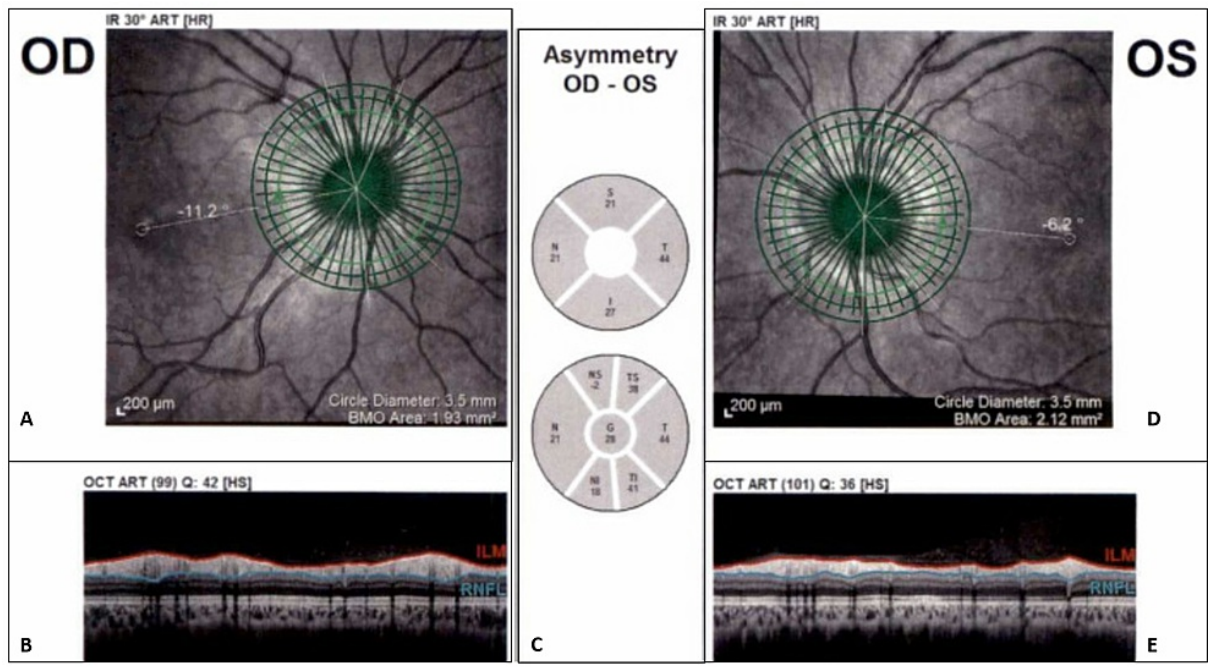

FIGURE 1: Laser tomography. (A) Right eye circle scan. (B) Right OCT scan with automatic segmentation of RNFL. (C) Differences between average thickness in sectors (along the calculation circle) in each eye. (D) Left eye circle scan. (E) Left OCT scan with automatic segmentation of RNFL.

Abbreviations: ART, automatic real-time; BMO, Bruch's membrane opening; HR, high resolution; HS, high speed; ILM, internal limiting membrane; IR, infrared reflectance imaging; OD, oculus dexter; OS, oculus sinister; OCT, optical coherence tomography; RNFL, retinal nerve fiber layer.

\section{Discussion}

COVID-19 has mainly affected the respiratory system leading to life-threatening complications causing significant mortality and morbidity. However, gastrointestinal, renal, cardiac, neurological, and ocular complications have also been described in the literature [5].

The ophthalmic mode of transmission of the coronavirus has not been well studied. In 2004, human coronavirus NL63 was detected in a seven-month-old child who presented with bronchiolitis and conjunctivitis. The virus was found in tear samples of many patients [6]. Interestingly, feline coronavirus (which affects cats) and murine coronavirus (which affects mice) have caused ocular complications in humans probably because of underlying vasculitis $[7,8]$.

COVID-19 is caused by a beta-coronavirus that uses the angiotensin-converting enzyme-2 receptor (ACE2) to enter cells. The ACE2 receptor is widely expressed in the central nervous system, including the retina and its vessels [9-11]. The ocular vascular microangiopathy in COVID-19 patients could be due to a hypercoagulable state or vasculitis, but further studies are warranted.

Our case was extensively investigated, and all other probable causes, including infection and immunemediated etiologies of optic neuritis, were ruled out. Agrawal et al. reported that steroids are the mainstay of noninfectious uveitis treatment [12], although the treatment of optic neuritis in children due to COVID19 has not been described in the literature. The World Health Organization declared a public health emergency of international concern on January 30, 2020, and recommended using goggles and a face shield to prevent the ocular transmission of the virus $[13,14]$. Additional studies are warranted to determine the etiopathogenesis and management of ocular manifestations of COVID-19.

\section{Conclusions}

COVID-19 is a multisystem disorder. Ocular manifestations, such as conjunctivitis and optic neuritis, are rare but should not be ignored. Physicians should consider a detailed evaluation of patients using fundoscopy and MRI of the orbit when necessary. Steroids are the mainstay of treatment, but additional studies are recommended to explore the disease and successful treatments.

\section{Additional Information}

\section{Disclosures}

Human subjects: Consent was obtained or waived by all participants in this study. Conflicts of interest: In 
compliance with the ICMJE uniform disclosure form, all authors declare the following: Payment/services info: All authors have declared that no financial support was received from any organization for the submitted work. Financial relationships: All authors have declared that they have no financial relationships at present or within the previous three years with any organizations that might have an interest in the submitted work. Other relationships: All authors have declared that there are no other relationships or activities that could appear to have influenced the submitted work.

\section{References}

1. Salata C, Calistri A, Parolin C, Palù G: Coronaviruses: a paradigm of new emerging zoonotic diseases . Pathog Dis. 2019, 77:006. 10.1093/femspd/ftaa006

2. Schalk AF, Hawn MC: An apparently new respiratory disease of baby chicks . J Am Vet Med Assoc. 1931, 78:413-423.

3. Tyrrell DA, Fielder M: Cold wars: the fight against the common cold . Oxford University Press, Oxford; 2002. 10.1016/j.jcv.2008.04.002

4. Loon SC, Lun K: SARS: a timely reminder. Br J Ophthalmol. 2013, 97:1217-1218. 10.1136/bjophthalmol2013-303596

5. Chen N, Zhou M, Dong X, et al.: Epidemiological and clinical characteristics of 99 cases of 2019 novel coronavirus pneumonia in Wuhan, China: a descriptive study. Lancet. 2020, 395:507-513. 10.1016/S0140 6736(20)30211-7

6. van der Hoek L, Pyrc K, Jebbink MF, et al.: Identification of a new human coronavirus . Nat Med. 2004, 10:368-373. 10.1038/nm1024

7. Hohdatsu T, Okada S, Ishizuka Y, Yamada H, Koyama H: The prevalence of types I and II feline coronavirus infections in cats. J Vet Med Sci. 1992, 54:557-562. 10.1292/jvms.54.557

8. Kipar A, May H, Menger S, Weber M, Leukert W, Reinacher M: Morphologic features and development of granulomatous vasculitis in feline infectious peritonitis. Vet Pathol. 2005, 42:321-330. 10.1354/vp.42-3-321

9. Hooks JJ, Percopo C, Wang Y, Detrick B: Retina and retinal pigment epithelial cell autoantibodies are produced during murine coronavirus retinopathy. J Immunol. 1993, 151:3381-3389.

10. Zhang H, Penninger JM, Li Y, Zhong N, Slutsky AS: Angiotensin-converting enzyme 2 (ACE2) as a SARSCoV-2 receptor: molecular mechanisms and potential therapeutic target. Intensive Care Med. 2020, 46:586590. 10.1007/s00134-020-05985-9

11. Duan Y, Beli E, Li Calzi S, et al.: Loss of angiotensin-converting enzyme 2 exacerbates diabetic retinopathy by promoting bone marrow dysfunction. Stem Cells. 2018, 36:1430-1440. 10.1002/stem.2848

12. Agrawal R, Testi I, Lee CS, et al.: Evolving consensus for immunomodulatory therapy in noninfectious uveitis during the COVID-19 pandemic. Br J Ophthalmol. 2020, 2020:316776. 10.1136/bjophthalmol-2020316776

13. World Health Organization: Statement on the second meeting of the international health regulations (2005) emergency committee regarding the outbreak of novel coronavirus (2019-nCoV). 2020, 2021:30-01.

14. World Health Organization: Infection prevention and control during health care when novel coronavirus (nCoV) infection is suspected. 2020, 2021:10665-331495. 